\title{
Comparison of flow pressures in different 3-way infusion devices: an in-vitro study
}

\author{
Jonathan Chua* (D) and Arun Ratnavadivel
}

\begin{abstract}
Background: The use of multiple infusions through one cannula is an increasingly common practice in anaesthesia. High pressures in the line often lead to occlusion alarms and pump disconnection. In this study, we aim to determine the pressures generated in common 3-way infusion devices, using simple low-cost equipment available and currently in use in the operating theatre environment.

Methods: We compared three different common and commercially available 3-way infusion devices that allowed multiple infusions through one cannula in vitro. One with anti-siphon valves, one without valves, and serial extension sets with side ports connected in series. An invasive blood pressure transducer was used to monitor line pressure. Seven different infusion rates were used to simulate different infusions.

Results: 3-way infusion devices with anti-siphon valves have 5.5 times the infusion pressures compared to devices without valves $(P<0.001)$. The highest pressures obtained across all devices were at the highest flow rate studied $(400 \mathrm{ml} / \mathrm{hr})$; this was $243 \mathrm{mmHg}$ in the 3-way device with anti-siphon valves, compared to only $44 \mathrm{mmHg}$ in the 3-way device without valves and $36 \mathrm{mmHg}$ in the serial extension sets. Serial extension sets have the lowest pressures across all flow rates when compared to 3-way devices without valves. $(P=0.0001)$.

Conclusions: The presence of anti-siphon valves generate very high pressures in infusion lines that can contribute to occlusion alarm disconnection of a pump. However, when measured alone and in-vitro, these pressures are not sufficient to trigger occlusion alarms. There are 3-way infusion devices without anti-siphon valves that have lower line pressures, but clinicians should be aware of negative pressure scenarios which can lead to siphoning when using them.
\end{abstract}

Keywords: Transducers, Pressure, Infusion pumps

\section{Background}

The administration of multiple infusions via one intravenous cannula is becoming increasingly common in the practice of anaesthesia. High pressures in the line often lead to occlusion alarm and pump disconnection, which makes it important to understand what contributes to raised line pressures.

The advent of new drugs and introduction of target-controlled infusion (TCI) pumps has made total intravenous anaesthesia (TIVA) a growing technique over the last 20 years. It offers advantages over traditional inhalational anaesthesia, including: improved quality of emergence; reduced postoperative nausea and

\footnotetext{
* Correspondence: jonathan.chua@health.nsw.gov.au

Department of Anaesthesia, Nepean Hospital, Kingswood, NSW 2747,
} Australia

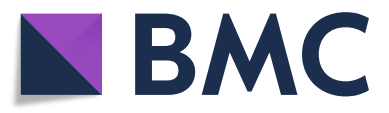

(c) The Author(s). 2018 Open Access This article is distributed under the terms of the Creative Commons Attribution 4.0 International License (http://creativecommons.org/licenses/by/4.0/), which permits unrestricted use, distribution, and reproduction in any medium, provided you give appropriate credit to the original author(s) and the source, provide a link to the Creative Commons license, and indicate if changes were made. The Creative Commons Public Domain Dedication waiver (http://creativecommons.org/publicdomain/zero/1.0/) applies to the data made available in this article, unless otherwise stated. vomiting; and earlier discharge in outpatient surgery [1, 2 , 3]. In these cases, multiple infusions consisting of intravenous (IV) fluids, propofol, and remifentanil are often administered through a single cannula.

In order to deliver a drug, infusion pumps generate a force to overcome resistive forces and venous pressure. When such pressures exceed a set limit, occlusion alarms sound and a protective disconnect of the pump motor is initiated to prevent harm to the patient. Hence, thoughtful setup of infusion systems including the lines to avoid high pressures is important to avoid pump failure. The impetus for this study arose from anecdotal reports of increased incidence of occlusion alarms from members of our department after the introduction of a new 3-way infusion device with anti-siphon valves. We aimed to study the pressures generated in common types 
of 3-way infusion devices, using simple low-cost equipment available and currently in use in the operating theatre environment.

\section{Methods}

We compared three different common and commercially available infusion devices that allowed multiple infusions through one cannula in vitro. A commercially available syringe infusion pump (Perfusor Space, B.Braun, Melsungen, Germany) containing a Luer lock $20 \mathrm{~mL}$ syringe (Terumo, Somerset, NJ, USA) was connected to a $205 \mathrm{~cm}$ extension set (Becton Dickinson, Franklin Lakes, NJ, USA). The extension line was then connected to a 3-way stopcock (Becton Dickinson). An invasive blood pressure transducer (TruWave, Edwards, Irvine, CA, USA) was connected to the middle stopcock to monitor line pressure. The distal stopcock was connected to the three different 3-way infusion devices. One with anti-siphon valves (500-003 V, Carefusion, Hampshire, UK); (Fig. 1), one 3-way device without valves (BC 6004, REM SYSTEMS, New Zealand); (Fig. 2), and serial extension sets with side ports connected in series (30842E,

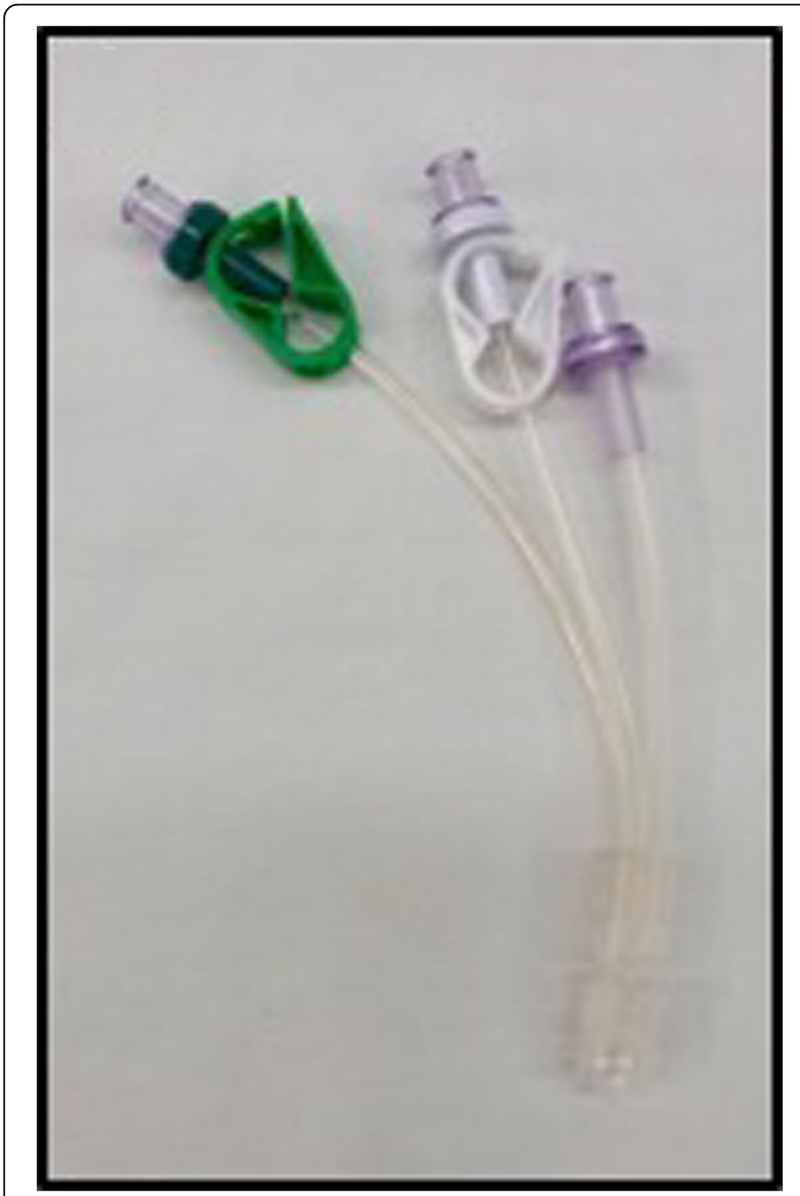

Fig. 1 3-way device with anti-siphon valves

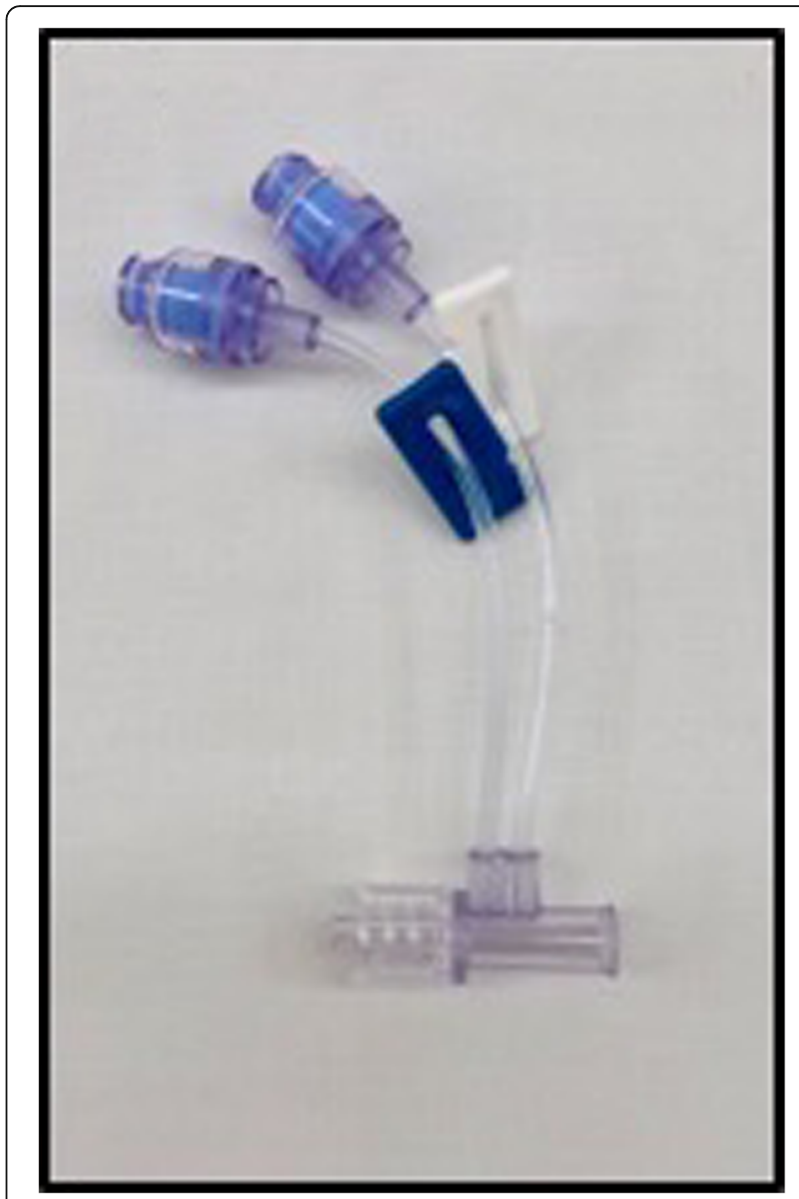

Fig. 2 3-way device without valves

Becton Dickinson); (Fig. 3). A summary of their features is shown in Table 1. Each set was then connected to a needle-free valve (2000E, Carefusion) and 20G cannula (Introcan, B.Braun) opened to air. All components were positioned at the same level to eliminate any pressure effects of gravity. The experimental setup was chosen to reflect clinical practice and is shown in Figs. 4 and 5.

Seven different infusion rates were chosen to simulate the infusion of vasopressors, propofol, or remifentanil $(10,20,30,40,50,100$, and $400 \mathrm{ml} / \mathrm{hr})$. The syringe and lines were filled with normal saline, with care taken to evacuate all air bubbles. A simultaneous gravity infusion of carrier fluid was set up with normal saline running from a bag suspended $1 \mathrm{~m}$ above the setup. The pressure ("mean arterial pressure") measured by the arterial line transducer was recorded at each flow rate after $60 \mathrm{~s}$ of flow. Pressures at each flow rate was measured three times and the experiment repeated again with another set of 3-way devices. Results were analyzed using the paired t-test. All data are given as mean $\pm S D$, with $P$ values $<0.05$ considered statistically significant. 


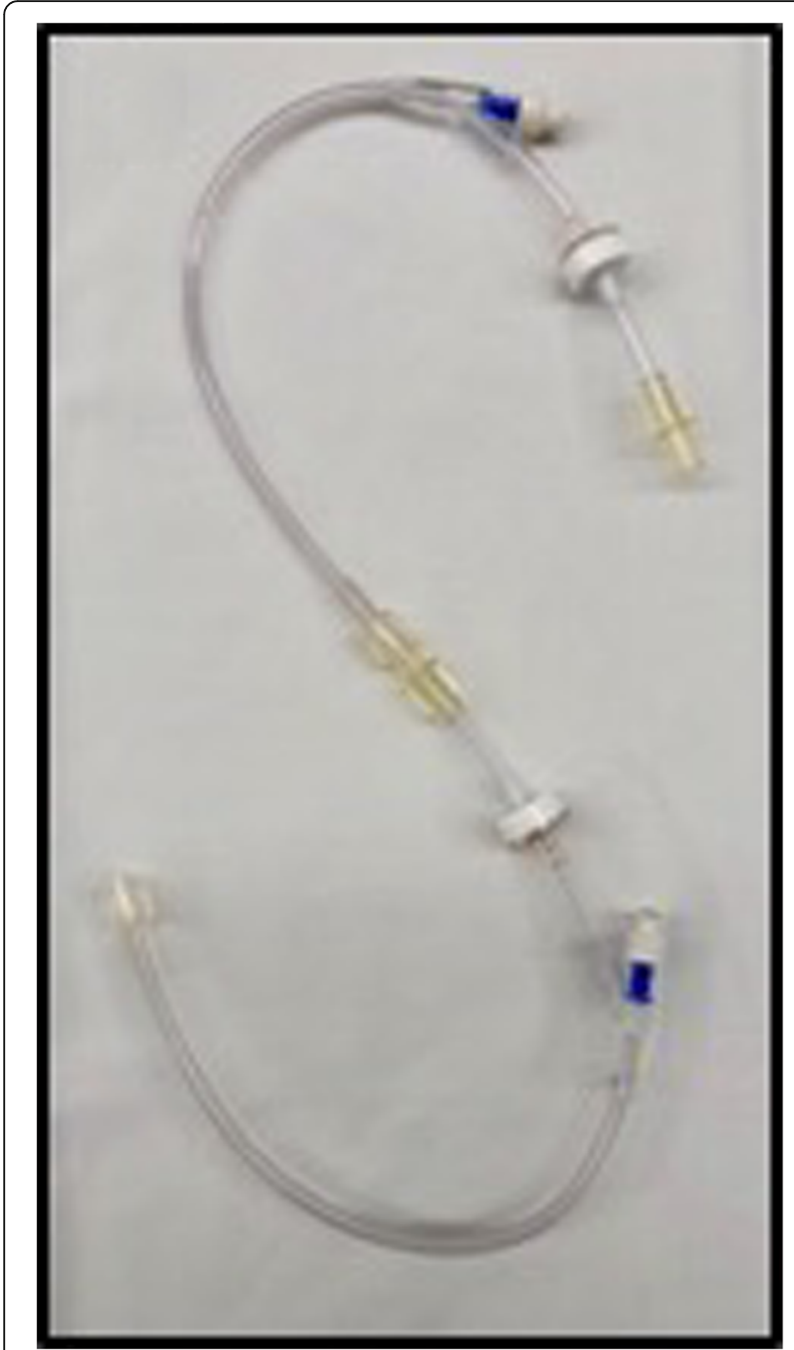

Fig. 3 Two extension sets with side ports connected in series

\section{Results}

3-way devices with anti-siphon valves (A) have much higher infusion pressures than devices without valves (B) $(P<0.001)$; (Fig. 6). The highest pressures obtained across all devices were at the highest flow rate; this was $243 \mathrm{mmHg}$ in the 3-way device with anti-siphon valves (A), compared to only $44 \mathrm{mmHg}$ in the 3 -way device without valves (B) and $36 \mathrm{mmHg}$ in the serial extension sets $(C)$. Serial extension sets $(C)$ have the lowest pressures across all flow rates when compared to 3-way

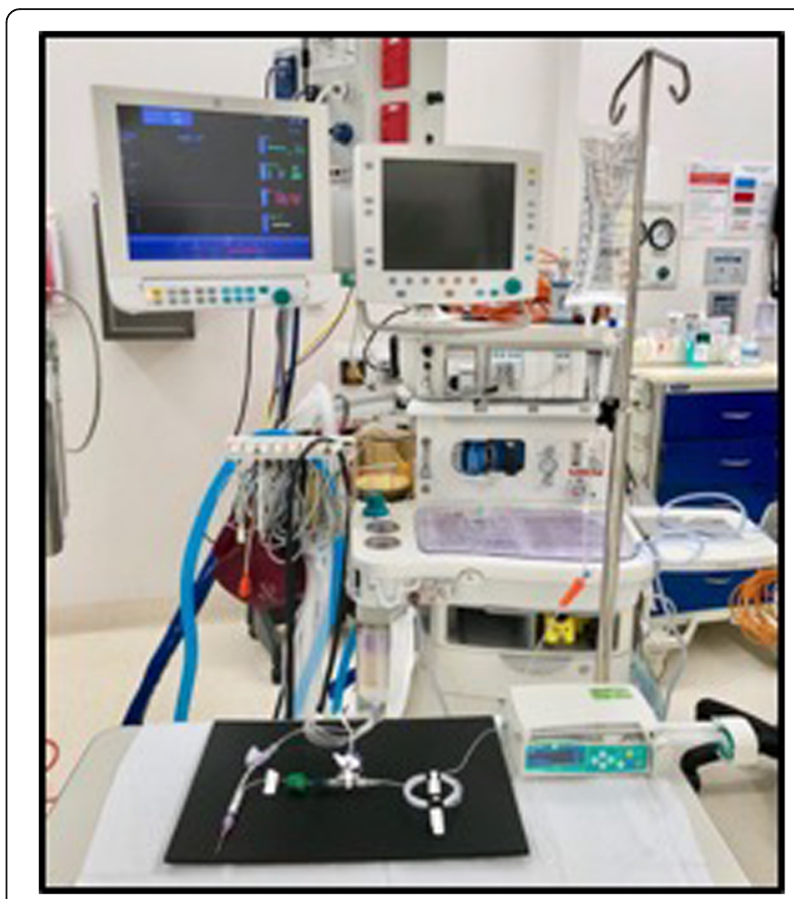

Fig. 4 Full arrangement showing experimental setup connected to a syringe pump, bag of fluids, and the anaesthetic machine to display pressures

devices without valves (B) $(P=0.0001)$; (Fig. 6). Results are shown in Table 2. All results were repeatable with low standard deviations.

\section{Discussion}

This is the first study to determine and compare the pressures in commonly used 3-way infusion devices using simple low-cost equipment employed in the operating theatre environment.

Our study reveals that the presence of anti-siphon valves increases infusion pressures considerably and proportionally to flow rate. These pressures are much higher than the quoted opening pressures of $100-$ $150 \mathrm{mmHg}$ [4]. Across all flow rates, 3-way devices with anti-siphon valves developed approximately 5.5 times more pressure than devices without valves. Anti-siphon valves work by opening at a certain overpressure. Their importance is to prevent free flow of an infusion should negative pressure develop in the line. This can occur by positioning a disconnected syringe above the patient.

Table 1 Characteristics of the different infusion devices tested

\begin{tabular}{|c|c|c|c|c|}
\hline Infusion device & Type of access & Anti-siphon valve? & One-way valve on fluid line? & Dead-space \\
\hline $\bar{A}$ & 3-way with anti-siphon valves & Yes & Yes & $0.3-0.6 \mathrm{ml}$ \\
\hline B & 3-way without valves & No & No & $0.3 \mathrm{ml}$ \\
\hline C & Serial extension sets in series & No & Yes & $2.4 \mathrm{ml}$ \\
\hline
\end{tabular}




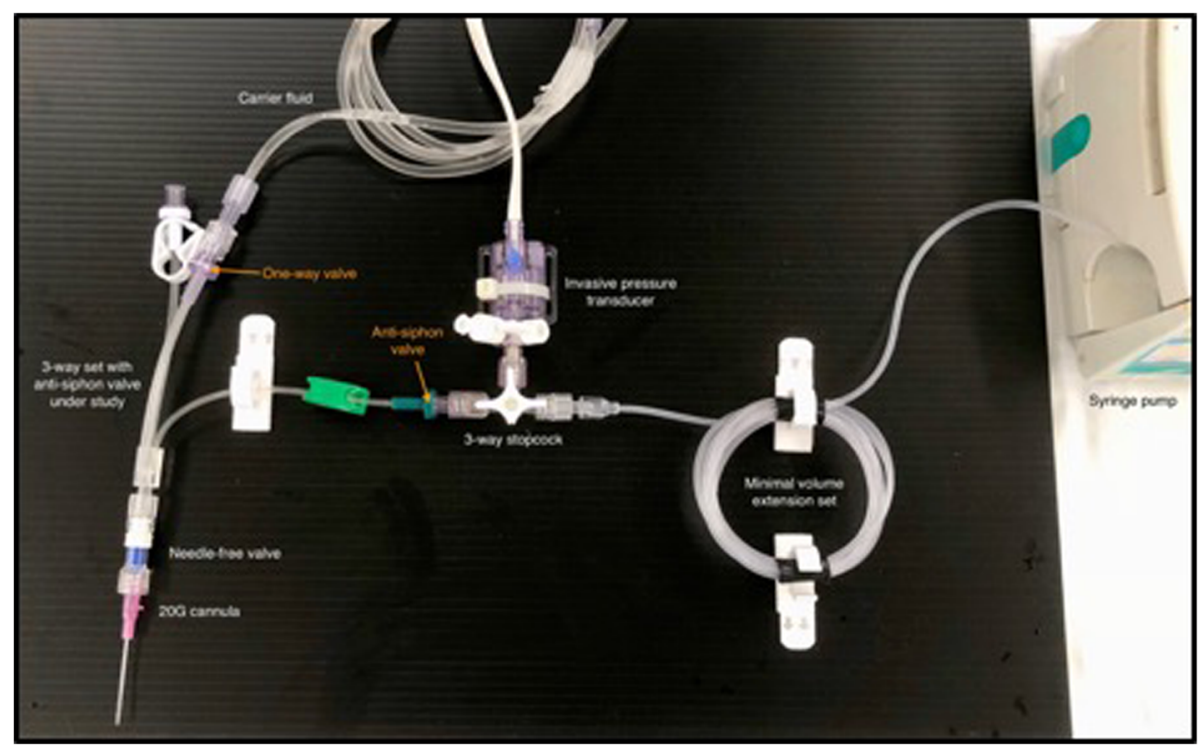

Fig. 5 Close-up of experimental setup

Where there is a possibility of air entering the syringe, through cracks or an open stopcock, the level of the syringe needs only to be a few centimeters above the venous pressure to allow free flow of an infusion. This deleterious situation has been reported in the literature [4] with serious consequences to the patient. Despite the high pressures, we did not encounter occlusion alarms in-vitro with our pump occlusion alarm set at $500 \mathrm{mmHg}$, a default pressure used by many manufacturers. This suggests that a combination with other factors in-vivo is required for tripping the pump occlusion alarm. These are likely patient related, such as cannula positioning, and are beyond the scope of this study. Certainly, the presence of anti-siphon valves will reduce the threshold for the presence of these other factors. Technical data on the Perfusor Space pump reveal that occlusion pressures can be set between 75 and $900 \mathrm{mmHg}$. Indeed, if configured at the lowest setting, the pump would not work with the anti-siphon devices but will function with the other devices tested here.

Despite the lower pressures, the other devices studied have short-comings. The 3-way device without valves (B) do not have one-way valves along the gravity fluid port. Should the cannula be occluded, the contents of pump infusion will flow into the higher compliance fluid line. The pressure rise may take some time before occlusion alarms sound. Having one-way valves would reduce this delay and has been shown to increase the accuracy of drug delivery [5].

The serial extension sets (C) studied possess one-way valves and have the advantage of the lowest pressures. This can be attributed to a larger internal diameter.

\section{Comparison of different 3-way setups}

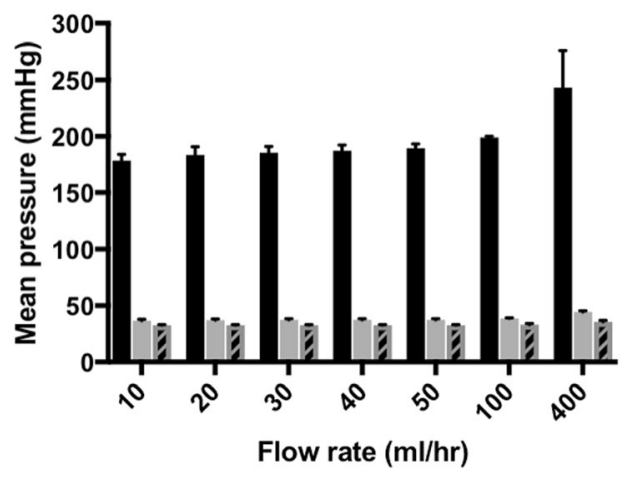

3-way with anti-siphon valves

3-way without valves

Serial extension sets

Fig. 6 Pressures of different 3-way setups at different flow rates 
Table 2 Pressures encountered at different flow rates across the three devices tested

\begin{tabular}{llll}
\hline \multirow{2}{*}{ Flow rate $(\mathrm{ml} / \mathrm{hr})$} & \multicolumn{2}{l}{ Mean pressure $(\mathrm{mmHg})$} \\
\cline { 2 - 3 } & A-way with anti-siphon valves & \multicolumn{2}{l}{$\begin{array}{l}\text { S-way without valves } \\
\text { B }\end{array}$} \\
\hline 10 & $178.7 \pm 6$ & $36.7 \pm 1$ & $32.7 \pm 1$ \\
20 & $183.7 \pm 7$ & $37.0 \pm 1$ & $32.7 \pm 1$ \\
30 & $185.7 \pm 6$ & $37.3 \pm 1$ & $32.7 \pm 1$ \\
40 & $187.3 \pm 5$ & $37.3 \pm 1$ & $32.7 \pm 1$ \\
50 & $189.7 \pm 4$ & $37.3 \pm 1$ & $32.7 \pm 1$ \\
100 & $199.0 \pm 1$ & $38.7 \pm 1$ & $33.0 \pm 1$ \\
400 & $243.3 \pm 33$ & $44.3 \pm 1$ & $35.7 \pm 1$ \\
\hline
\end{tabular}

However, this brings about a total dead-space volume of $2.4 \mathrm{ml}$, compared to $0.3-0.6 \mathrm{ml}$ in the other 3-way devices. Delay in reaching the targeted drug delivery rate has been shown to be directly related to dead-space volume [6]. Up to an extra $5 \mathrm{~min}$ lag time for drug delivery has been found in devices with high dead-space volumes [7].

Our study has some limitations. We did not use commercial pressure transducers. This has implications on the accuracy of low pressure measurement and limiting measurements to $320 \mathrm{mmHg}$. Because of this, we did not test higher flow rates $(>400 \mathrm{ml} / \mathrm{hr}$ ) which generated pressures beyond what we could measure. The use of different infusion line arrangements, pumps, syringes, and cannula size would be expected to yield different pressures than those found in our study which limits its generalizability. Also, we used normal saline instead of specific drugs which may influence the frictional forces in the syringe and infusion lines. However, it remains likely that the highest pressure encountered in any infusion line is due to the presence of an anti-siphon valve.

\section{Conclusion}

The ideal multi-infusion device would have the following properties: low resistance, low dead-space, anti-siphon valves, and one-way valves on carrier fluid lines. As we have seen from our study, the devices available and commonly used in practice have some but not all of these qualities. The implications for practice is the clinician must understand the limitations of the device being used. For example, if high occlusion pressures are encountered despite a functioning cannula and a line free from occlusion, a solution may be to change to a setup without anti-siphon valves. However, one must keep in mind that in doing so removes a layer of safety and must be vigilant against situations that can lead to siphoning as covered above.

In conclusion, anti-siphon valves generate considerably higher pressures in infusion lines, especially at bolus flow rates, but such pressures alone are not high enough to trip pump occlusion alarms if set appropriately. Their presence would certainly reduce the threshold for other causes of raised line pressures being present before occlusion alarms are tripped. There are multi-infusion devices without anti-siphon valves that produce lower line pressures, but clinicians should be aware of the risk of siphoning when using them.

\section{Funding \\ This study is not in receipt of any funding.}

Availability of data and materials

The datasets used and/or analysed during the current study are available from the corresponding author on reasonable request.

\section{Authors' contributions}

JC performed and interpreted the data regarding line pressures. AR was a major contributor in writing the manuscript. All authors read and approved the final manuscript.

Ethics approval and consent to participate Not applicable.

Consent for publication

Not applicable.

\section{Competing interests}

The authors declare that they have no competing interests.

\section{Publisher's Note}

Springer Nature remains neutral with regard to jurisdictional claims in published maps and institutional affiliations.

Received: 19 April 2018 Accepted: 13 June 2018

Published online: 29 June 2018

\section{References}

1. Lerman J, Jöhr M. Inhalational anesthesia vs total intravenous anesthesia (TIVA) for pediatric anesthesia. Pediatr Anesth. 2009;19(5):521-34.

2. Chandler JR, Myers D, Mehta D, Whyte E, Groberman MK, Montgomery CJ, Ansermino JM. Emergence delirium in children: a randomized trial to compare total intravenous anesthesia with propofol and remifentanil to inhalational sevoflurane anesthesia. Pediatr Anesth. 2013;23(4):309-15.

3. Kumar G, Stendall C, Mistry R, Gurusamy K, Walker D. A comparison of total intravenous anaesthesia using propofol with sevoflurane or desflurane in ambulatory surgery: systematic review and meta-analysis. Anaesthesia. 2014; 69(10):1138-50.

4. Sundaram $R$, Dell $A E$. Interaction between infusion equipment resulting in drug overdose in a critically ill patient. Anaesthesia. 2005;60(1):88-91. 
5. Décaudin B, Dewulf S, Lannoy D, Simon N, Secq A, Barthélémy C, Debaene $B$, Odou P. Impact of multiaccess infusion devices on in vitro drug delivery during multi-infusion therapy. Anesth Analg. 2009;109(4):1147-55.

6. Lovich MA, Kinnealley ME, Sims NM, Peterfreund RA. The delivery of drugs to patients by continuous intravenous infusion: modeling predicts potential dose fluctuations depending on flow rates and infusion system dead volume. Anesth Analg. 2006;102(4):1147-53.

7. Lannoy D, Décaudin B, Dewulf S, Simon N, Secq A, Barthélémy C, Debaene B, Odou P. Infusion set characteristics such as antireflux valve and dead-space volume affect drug delivery: an experimental study designed to enhance infusion sets. Anesth Analg. 2010;111(6):1427-31.

Ready to submit your research? Choose BMC and benefit from:

- fast, convenient online submission

- thorough peer review by experienced researchers in your field

- rapid publication on acceptance

- support for research data, including large and complex data types

- gold Open Access which fosters wider collaboration and increased citations

- maximum visibility for your research: over $100 \mathrm{M}$ website views per year

At BMC, research is always in progress.

Learn more biomedcentral.com/submissions 